\title{
Ambientes e paleoterritórios em faixas de fronteira: perspectivas para a História Ambiental
}

Willian Andrion do Valle ${ }^{1}$

\begin{abstract}
RESUMO
O presente trabalho faz uma breve análise de como a abordagem paleoterritorial pode contribuir para a pesquisa ambiental nas faixas de fronteira, marcadas por distintas temporalidades, diferenças em termos de produção e organização do território, além da presença de formações florestais e áreas protegidas que ultrapassam os limites internacionais. São apresentados os conceitos de ambiente e território e suas importantes imbricações, o que se mostrou um pré-requisito para a discussão sobre paleoterritórios e fronteiras. Tudo isso antecedido por uma apreciação sobre o contexto do surgimento, os objetivos e perspectivas da História Ambiental. O paleoterritório é definido como espacialização das resultantes ecológicas de territorializações passadas e aparece como uma contribuição relevante para analisar o passado a partir de novas perspectivas. São mencionados exemplos de relações fronteiriças articuladas à questão ambiental e que, por isso, servem como referencial para os estudos históricos sensíveis ao tema.
\end{abstract}

Palavras-chave: Paleoterritório; Ambiente; Fronteira; História Ambiental. 


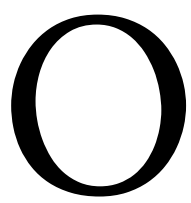

s graves quadros de degradação ambiental, cada vez mais difundidos por ativismos sociais e veículos de comunicação, desde meados do século passado, cimentaram caminho não apenas para uma requalificação da política internacional ${ }^{2}$, mas também para que as ciências sociais stricto sensu se vissem estimuladas a considerar o ambiente em seus currículos ou mesmo em seus enfoques acadêmicos. Assim, surgiram importantes subcampos disciplinares, como a Sociologia Ambiental e a História Ambiental.

Coube à História produzir novas leituras sobre o passado, valorizando a dimensão ambiental e sua influência nas atividades humanas. Essa nova perspectiva direcionou historiadores e demais cientistas sociais ao estudo dos processos (geo)ecológicos e abriu caminho para a necessária vinculação entre ambiente e território. Nesse contexto, os trabalhos de Rogério Ribeiro de Oliveira ${ }^{3}$ apresentaram o paleoterritório como importante recurso metodológico para a investigação das marcas inscritas na paisagem a partir de antigas territorializações. Assim, o paleoterritório aparece como a espacialização de resultantes ecológicas do trabalho humano e de atividades econômicas pretéritas.

Essa perspectiva direcionou o olhar do presente autor para as faixas de fronteira, espaços de grande interação e que constituem um campo fértil para estudos em História Ambiental. Este artigo surge como uma reflexão preparatória sobre o assunto e seu texto foi organizado em quatro seções, que compreendem: 1) considerações sobre o surgimento e os objetivos da História Ambiental, 2) a estreita relação entre ambientes e territórios, 3) o conceito de paleoterritório e 4) uma leitura das faixas de fronteira que considera os paleoterritórios.

\footnotetext{
${ }^{2}$ Materializada na realização de grandes encontros mundiais (a começar pela conferência realizada em Estocolmo, em 1972) e na formulação de agendas de governo, fundamentalmente pelos países centrais, com propostas e estratégias de ação para mitigar os problemas relacionados à poluição atmosférica, à contaminação do solo e dos mananciais de água e aos impactos associados ao uso de energia fóssil.

3 1) Rogério Ribeiro de Oliveira, "Mata Atlântica, paleoterritórios e História Ambiental", Ambiente e Sociedade, $n^{\circ} 2$, (2007): 11-23; 2) Rogério Ribeiro de Oliveira, "Fruto da terra e do trabalho humano: paleoterritórios e diversidade da Mata Atlântica no sudeste brasileiro", Revista de História Regional, $n^{\circ}$ 20-2, (2015): 277-299; 3) Rogério Ribeiro de Oliveira, Patrícia Delamônica, Denise Flores Lima e Daniel Toffoli, "A gênese estrutural de um paleoterritório: a sucessão na floresta atlântica nos primeiros dez anos após uso por populações caiçaras", Pesquisa Botânica, vol. 59, (2008): 113128.
} 


\section{SOBRE A HISTÓRIA AMBIENTAL}

A História Ambiental foi profundamente influenciada pelo ambientalismo emergente nos anos 1970. Como bem observou José Augusto Pádua ${ }^{4}$, os historiadores ambientais foram desafiados por uma nova compreensão sobre o papel do mundo natural e de sua relação com a vida humana. Para utilizar a construção de Donald Worster, um importante pesquisador sobre o tema, o principal objetivo da jovem História Ambiental seria "aprofundar o nosso entendimento de como os seres humanos foram, através dos tempos, afetados pelo seu ambiente natural e, inversamente, como eles afetaram esse ambiente e com que resultados"5.

Essa nova perspectiva, ao lançar luz sobre os impactos da ação humana no ambiente e vice versa, levou a História para além das tradicionais abordagens inscritas no campo da política, da economia e da cultura. A História Ambiental não apenas muda a maneira de investigar o passado, ela também abre possibilidades analíticas mais abrangentes para o futuro, aqui incluídas as discussões sobre o desenvolvimento sustentável, em múltiplas escalas. Noutros termos, a inclusão do meio ambiente no ementário da História permitiu propor novos temas e paradigmas de pesquisa ou, como bem destacou Cláudia Leal ${ }^{6}$, "también ha servido para mirar con nuevos ojos viejos problemas históricos"7.

Em grande parte, pode-se admitir que a negligência no tratamento das questões ambientais durante o século XIX, quando da institucionalização da História como disciplina acadêmica, esteve muito associada aos fantasmas das formulações deterministas e dos reducionismos, fortemente criticados pelas Ciências Sociais. Entretanto, como afirma José Augusto Pádua, atualmente, a História Ambiental se encontra em um contexto teórico diferente, marcado pela "visão de uma natureza em permanente movimento e transformação ao longo do tempo [o que], obviamente, não favorece a capacidade de persuasão de teorias deterministas"

\footnotetext{
4 José Augusto Pádua, "As bases teóricas da História Ambiental”, Estudos Avançados, n 24 - 68, (2010): p.83.

5 Donald Worster, "Para fazer História Ambiental", Estudos Históricos, vol. 4 - n 8, (1991): p. 199.

${ }^{6}$ Claudia Leal, "Aguzar la mirada colectiva, el gran desafío de la Historia Ambiental latinoamericana”, Historia Social, vol.36, (2019): p. 247.

${ }^{7} \mathrm{Na}$ tradução do autor: também serviu para olhar para velhos problemas históricos com novos olhos.

8 José Augusto Pádua, "As bases teóricas da História Ambiental”, Estudos Avançados, n 24 - 68, (2010): p. 90.
} 
Com efeito, a História Ambiental se engajou no projeto de romper (em uma avaliação mais utópica) ou minimizar (o que se mostra mais exequível) a forte dicotomia entre sociedade e natureza. José Augusto Drummond chegou a afirmar que a originalidade da História Ambiental reside na sua "disposição explícita de colocar a sociedade na natureza e no equilíbrio com que busca a interação, a influência mútua entre sociedade e natureza"9, o que obviamente exige dos historiadores um mergulho nos estudos e metodologias (geo)ecológicos ${ }^{10}$, tarefa árdua e, frequentemente, negligenciada por cientistas pouco familiarizados com as ciências naturais. Em que pese o fato de o referido autor ter cometido um lapso, ao atribuir à História, e não à Geografia, a originalidade nos estudos do par sociedade/natureza, sua constatação acerca do campo de atuação da História Ambiental é muitíssimo proveitosa para os propósitos deste artigo. A discussão sobre sociedade e natureza já ocupava a atenção de geógrafos, pelo menos, desde o final do século XIX, portanto, muito antes do aparecimento da História Ambiental. A esse respeito, Paulo César Gomes escreveu: “(...) esta definição da Geografia como campo de relações entre sociedade e natureza é apenas uma revitalização da imagem do homem-meio que dominou a reflexão geográfica na passagem do século [XIX para o XX]”11.

É importante destacar que embora exista alguma diferenciação epistemológica/metodológica entre sociedade e natureza, como sugerido por Marcelo Lopes de Souza, ela não deve ser inflexível a ponto de criar uma completa clivagem entre os dois conceitos. Há imbricações, estímulos mútuos, sobreposições entre cultura (sociedade) e natureza, e o seu reconhecimento "reforça a convicção de que o ambiente não é algo simplesmente externo ao indivíduo (...), mas sim algo que interage intimamente com os indivíduos"12.

O qualificativo ambiental, que define o subcampo científico de que trata esse pequeno artigo, ou mesmo o ambiente, sua versão substantiva, não poderiam deixar de

\footnotetext{
${ }^{9}$ José Augusto Drummond, “A História Ambiental: temas, fontes e linhas de pesquisa", Estudos Históricos, Rio de Janeiro, vol.4 - n 8, (1991): p. 185.

10 O termo (geo)ecológico aponta a necessidade de as reflexões da Ecologia estarem em diálogo com contextos e escalas de análise propostos pela Geografia. Trata-se de uma proposta de estudo interdisciplinar do meio ambiente.

11 Paulo Cesar da Costa Gomes, "Geografia fin-de-siècle: o discurso sobre a ordem espacial do mundo e o fim das ilusões". In: Explorações geográficas, organizado por Iná Elias de Castro, Paulo César da Costa Gomes e Roberto Lobato Corrêa (Rio de Janeiro: Bertrand Brasil, 1997): p. 27.

12 Marcelo Lopes de Souza, "Ambientes e territórios: uma introdução à Ecologia Política" (Rio de Janeiro: Bertrand Brasil, 2019): p. 52-55.
} 
receber uma atenção especial: isso porque não há sentido em estudar/propor História Ambiental sem que se compreenda o que é ambiente. O conceito de ambiente está relacionado a uma nova perspectiva de mundo, a uma mudança de racionalidade e não deve ser entendido como um aprofundamento ou ajuste nos conceitos de ecologia ou natureza. Para Enrique Leff, o referido conceito:

(...) resignifica o olhar sobre as coisas e o mundo em uma ordem de complexidade inédita. Este novo olhar não é somente o salto de uma natureza primária para uma "natureza secundária", que passa a ser sobre-determinante da primeira. O saber ambiental transcende a posição culturalista, construtivista e hermenêutica sobre os diferentes sentidos da natureza; é a construção de um conceito que enlaça o material e o simbólico, o ente e o ser, o econômico e o ecológico, o interno e o externo, o objetivo e o subjetivo, o passado e o futuro. ${ }^{13}$

O ambiente articula, dessa forma, as relações, tensões e práticas sociais com a natureza e suas relações ecológicas, revestindo a vida de uma complexidade não apreensível quando se pensa nos processos (geo)ecológicos e nos processos sociais isoladamente.

Outra forma de conceber o conceito em tela é oferecida por Marcelo Lopes de Souza, para quem o ambiente sugere, mesmo que de forma reducionista, uma "conexão entre as ideias de espaço e natureza"14. Segundo o autor, o ambiente pode ter a mesma extensão do espaço geográfico ou até, dependendo da perspectiva em que se apoie, se revelar ainda mais amplo que este último.

O historiador ambiental não precisa se limitar, considerando o que foi exposto até aqui, a apenas produzir análises mais consistentes e complexas acerca das relações sociedade/natureza, ele pode reexaminar as fontes e documentos históricos a partir das novas concepções vigentes e reinterpretar, pelo menos parcialmente, a história da humanidade. Um movimento assim certamente demandaria um trabalho hercúleo, mas seu benefício teria um amplo alcance, contribuindo não apenas para uma releitura do

\footnotetext{
${ }^{13}$ Enrique Leff, "Construindo a História Ambiental da América Latina", Revista Esboços, n 13, (2003): p. 16.

14 Marcelo Lopes de Souza, "Ambientes e territórios: uma introdução à Ecologia Política" (Rio de Janeiro: Bertrand Brasil, 2019): p. 38.
} 
passado a partir de uma ótica ambiental, mas também para o amadurecimento das discussões sobre sustentabilidade, desastres e colapsos no ambiente.

Outro aspecto fundamental desse potencial revisionista ${ }^{15}$ atribuído à História Ambiental está em criar representações que evidenciem sujeitos e particularidades, até então, encobertos pelas densas camadas discursivas dos tradicionais relatos históricos. Uma forma de visibilizar os grupos que, subjugados e controlados por terceiros, não tiveram seus feitos reconhecidos ou, de outra parte, uma forma de compreender a degradação (geo)ecológica resultante de grandes empreendimentos ou dos processos de conquista territorial. Como bem considerou o epistemólogo Enrique Leff, "A história ambiental é, pois, a história de histórias não ditas; e não somente porque a natureza não fala e porque os pobres, os colonizados, os dominados e os vencidos foram silenciados, e sim porque a subjugação da natureza foi um processo silencioso, invisível e impensado"16.

Nesse contexto, as pesquisas em História Ambiental podem se basear em múltiplas escalas, desde a planetária (que tem como seu principal exemplo a mudança climática global) até escalas locais ou microlocais (através das quais, pode-se examinar uma encosta que tenha servido a atividades agropastoris ou mesmo um trecho de mata que tenha sido palco da produção de carvão vegetal), passando pela escala regional, que inclui estudos sobre áreas protegidas em faixas de fronteira.

O contexto geoeconômico dos grupos sociais que, através do seu trabalho, modificam o ambiente e o grau de resiliência dos ecossistemas implicados também devem pautar os referidos estudos históricos. Sabe-se, por exemplo, que as populações tradicionais costumam realizar atividades menos impactantes ambientalmente (com exceções, basta ver os impactos associados à pratica das queimadas ${ }^{17}$ ) do que as grandes empresas capitalistas responsáveis pela exploração de recursos ou do que foi o produtivismo soviético, muitíssimo poluente.

\footnotetext{
${ }^{15}$ A expressão "potencial revisionista" foi empregada contextualmente para indicar a possibilidade de historiadores dedicarem maior atenção à dimensão ambiental quando realizarem suas pesquisas, o que geraria ganho analítico. Como a expressão é controversa, cumpre esclarecer que não se pretendeu aqui apoiar o negacionismo histórico ou qualquer ideologia anticientífica.

${ }^{16}$ Enrique Leff, "Construindo a História Ambiental da América Latina", Revista Esboços, n 13, (2003): p. 18.

17 Vejam os trabalhos de Marcelo Lopes de Souza, "Ambientes e territórios: uma introdução à Ecologia Política" (Rio de Janeiro: Bertrand Brasil, 2019): p. 91 e José Augusto Drummond, "A História Ambiental: temas, fontes e linhas de pesquisa", Estudos Históricos, Rio de Janeiro, vol.4 - $n^{\circ} 8$, (1991): p. 189.
} 
A definição, ainda que introdutiva, do objeto de estudo da História Ambiental, abre caminho para discussão de seus métodos. O clássico trabalho de José Augusto Drummond $^{18}$ identificou cinco características analíticas e metodológicas desse novo ramo da História, a saber: 1) a maioria dos estudos apresenta um enfoque regional, com ênfase nos aspectos físicos e ecológicos; 2) há um diálogo sistemático com as ciências naturais, objetivando compreender os aspectos ecológicos das regiões estudadas; 3) existe uma preocupação em explorar a interação entre os recursos disponíveis e os diferentes "estilos civilizatórios das sociedades humanas"; 4) há grande variedade de fontes úteis para os estudos das relações sociedade/natureza: documentos diversos, censos, inventários, relatos de viajantes e naturalistas e, inclusive, etnografias; e 5) os trabalhos de campo, através dos quais o historiador faz observações e entrevistas in loco, constituem uma ferramenta de uso frequente.

Mesmo considerando que esse autor tenha feito esse painel metodológico há quase três décadas, sua avaliação ainda se mostra pertinente e pragmática. Com o aprofundamento do processo de globalização e a crescente importância dada à escala planetária para a investigação das ações antropogênicas, torna-se necessário confirmar se os estudos que privilegiam a abordagem regional ainda formam uma maioria absoluta dentre os que podem ser incluídos no campo da História Ambiental.

Os dois últimos itens mencionados, a variedade de fontes para a pesquisa ambiental e a realização de trabalhos de campo, merecem, inclusive, um destaque por enfatizarem procedimentos metodológicos imprescindíveis aos estudos ambientais lato sensu, não servindo apenas à História Ambiental.

O trabalho de campo não apenas possibilita a confirmação (ou eventual refutação) das informações obtidas pela pesquisa documental; ele abre possibilidades de o historiador interagir mais intensamente com seu objeto de estudo - ouvindo relatos, correlacionando as alterações ecológicas a determinadas práticas sócioespaciais (que, por sua vez, retratam diferentes perspectivas de natureza), identificando

18 José Augusto Drummond, "A História Ambiental: temas, fontes e linhas de pesquisa”, Estudos Históricos, Rio de Janeiro, vol.4 - $n^{\circ} 8,(1991): p$. 181. 
e analisando as marcas inscritas na paisagem -, o que abre caminho para o novo e o inaudito na tentativa de compreender a complexidade ambiental.

É importante destacar que as diferentes formas de apropriação e intervenção de grupos humanos no ambiente, quer para a geração de condições mínimas de existência desses grupos ou pela simples busca por monetização, deixam registros no solo, na cobertura vegetal e nos ambientes fluviais e glaciais. Identificar esses registros, que muitas vezes se sobrepõem, como ocorre em alguns sítios arqueológicos (guardadas as devidas proporções temporais), é importante para se decodificar a paisagem, face visível do ambiente, tomado aqui como sinônimo de espaço geográfico. O espaço geográfico compreende as complexas interações que os grupos humanos estabelecem entre si e com o (e a partir do) substrato físico que ocupam e transformam constantemente. Para os propósitos tratados neste artigo, espaço geográfico e ambiente poderão ser equivalentes em extensão desde que este último vá além da "natureza não humana e seus elementos e fatores bióticos e abióticos", acomodando em seu universo lógico "toda a matéria e todos os tipos de fluxos"19.

Os estudiosos das sociedades - historiadores e arqueólogos, principalmente estão mais acostumados a investigar as marcas, legados ou heranças do trabalho humano em ambientes urbanos, a exemplo do que ocorre em Roma, cidade repleta de evidências do passado em seu subsolo ${ }^{20}$, do que em ambientes de floresta, por exemplo. Contudo, não é raro que estes ambientes acumulem complexamente as marcas de diferentes processos ou atividades antropogênicas ao longo do tempo histórico, revelando, uma vez por outra, mais registros do passado do que determinadas cidades.

Fica implícito, portanto, que as florestas e demais ambientes que usualmente são classificados como naturais não constituem espaços propriamente intocados. Rogério Ribeiro de Oliveira corrobora com essa assertiva ao tratar dos impactos dos diferentes usos passados na constituição das florestas. Ele sugere que o termo Mata Atlântica

\footnotetext{
19 Marcelo Lopes de Souza, "Ambientes e territórios: uma introdução à Ecologia Política” (Rio de Janeiro: Bertrand Brasil, 2019 ): p. 36-37.

20 Há, inclusive, circuitos turísticos para o subterrâneo de Roma, onde são mostradas evidências do Império Romano ou do Cristianismo primitivo, como anuncia o site de www.viagemitalia.com (acesso em 04 de fevereiro de 2019).
} 
"pode ser uma decorrência da homogeneização de paisagens muito complexas, compostas por numerosas formações 'originalmente' muito distintas entre si (...)"21.

\section{AMBIENTES E TERRITÓRIOS}

Toda essa discussão não pode negligenciar o fato de que os ambientes são alterados pelas práticas e atividades sócio-espaciais; eles sofrem os efeitos da territorialidade humana ${ }^{22}$, ao mesmo tempo que a influenciam significativamente. Desse modo, os ambientes se tornam um palco interativo das relações de poder espacialmente delimitadas. As pesquisas inscritas no campo da História Ambiental, em função disso, não devem prescindir de uma abordagem territorial.

A relação complementar entre ambientes e territórios pode ser vista teoricamente sob o prisma da dimensão espacial, como sugeriu Marcelo Lopes de Souza no trecho a seguir:

O conceito de território, de toda sorte, é basicamente sócio-espacial: ou seja, ele nos remete, fundamentalmente, àquela dimensão do espaço geográfico que é o espaço social, que corresponde ao espaço geográfico material e imaterialmente produzido pela sociedade, que deve ser desvendado por meio de estratégias metodológicas desenvolvidas pela pesquisa social ou, mais precisamente, sócio-espacial. Já o conceito de ambiente é epistemológica e teoricamente, um híbrido: ele possui faces distintas e complementares que o tornam um conceito compartilhado pelas ciências da natureza e da sociedade, referente a uma realidade multifacetada cujo esclarecimento exige a solidariedade entre estratégias metodológicas bem diversas. ${ }^{23}$

Definir ambiente impõe desafios ainda maiores do que aqueles que são esperados para a compreensão do território, ainda que este, como se verá a seguir, dê conta das vertentes política econômica e cultural. O caráter híbrido associado ao conceito de ambiente demanda do historiador ambiental uma maior habilidade para

\footnotetext{
${ }^{21}$ Rogério Ribeiro de Oliveira, "Mata Atlântica, paleoterritórios e História Ambiental", Ambiente e Sociedade, n 2, (2007): p. 21

22 Entendida aqui como a(s) forma(s) como o poder é manifestado por diferentes grupos ou indivíduos humanos em contextos específicos.

${ }^{23}$ Marcelo Lopes de Souza, "Ambientes e territórios: uma introdução à Ecologia Política" (Rio de Janeiro: Bertrand Brasil, 2019): p. 38.
} 
relacionar diferentes perspectivas de análise, oriundas de segmentos científicos ainda muito distantes entre si. Se a discussão sobre território não é estranha à formação do historiador no Brasil, o mesmo não se pode dizer dos temas e conteúdos de Ecologia, Pedologia e Climatologia que, dentre outros, constituem o campo ambiental.

Embora interesse aqui definir território como um espaço demarcado pelo exercício de poder por indivíduos ou grupos humanos, cumpre mencionar que as primeiras teorizações mais consistentes sobre a territorialidade, conforme observa Rogério Haesbaert ${ }^{24}$, são atribuídas à Etologia, um ramo da Zoologia que estuda o comportamento animal ${ }^{25}$. Mesmo que a Geografia, a História e as demais Ciências Sociais (Sociologia, Antropologia e Ciência Política) não tenham sido pioneiras nas proposições conceituais sobre território e territorialidade, sua produção é hoje substancial.

O diálogo entre historiadores, geógrafos e demais cientistas sociais em relação ao conceito de território é, no entanto, praticamente inexistente, o que abriu caminho para a criação de discussões teóricas bem polissêmicas. Ciente disso, o autor supracitado $^{26}$ cuidou de inventariar e sistematizar as concepções de território em três vertentes básicas: a política (onde o território é "visto como um espaço delimitado e controlado, através do qual se exerce um determinado poder"), a simbólico-cultural (em que a "apropriação/valorização simbólica de um grupo em relação ao seu espaço vivido" resulta no território) e a econômica (o território aparece como "fonte de recursos e/ou incorporado no embate entre as classes sociais e na relação capitaltrabalho").

Há também como perceber e classificar o território em função da escala geográfica em que ocorre. Assim, ele pode ter abrangência nacional e corresponder aos domínios do Estado-nação, pode ser constituído nas escalas regional, local e (micro)local, resguardando sua definição por relações de poder, manifestadas por grupos ou sujeitos diversos. Dessa forma, o território nacional deverá conter vários territórios menores em seu interior, legal ou ilegalmente constituídos.

\footnotetext{
${ }^{24}$ Rogério Haesbaert, "O mito da desterritorialização: do "fim dos territórios" à multiterritorialidade" (Rio de Janeiro: Bertrand Brasil, 2004$)$ : p. 37.

${ }^{25}$ A utilização de expressões como "território dos leões", a "territorialidade dos lobos", tão difundidas em textos da Biologia, corrobora para essa compreensão.

${ }^{26}$ Rogério Haesbaert, "O mito da desterritorialização: do "fim dos territórios" à multiterritorialidade" (Rio de Janeiro: Bertrand Brasil, 2004$):$ p. 40.
} 
A perspectiva do território como parte do Estado-nação ${ }^{27}$ é bem anterior à compreensão de que existem territórios formados, por exemplo, por criminosos que controlam espaços segregados (como os traficantes de drogas em determinadas favelas no Rio de Janeiro) ou por grupos que praticam desflorestamento ou biopirataria em áreas protegidas. Na tentativa de compreender a formação de uma sociedade a partir de seu território, Antonio Carlos Robert de Morais chegou a sugerir a expressão "história territorial" 28 . Em se tratando do colonialismo, destacou o quadro demográfico e a disponibilidade de recursos naturais no continente americano como vetores da conquista territorial realizada pelos europeus. Pensando na formação territorial de um país, não há como deixar de relacionar território e ambiente. Não obstante, a compreensão de que os territórios se efetivam em diferentes escalas geográficas trouxe ganhos analíticos ainda maiores para a pesquisa social, pois abriu caminho para que diversas manifestações de poder pudessem ser adequadamente lidas no ambiente.

A propósito, como bem salientou Marcelo Lopes de Souza, os limites territoriais raramente coincidem com os limites das "feições naturogênicas" ${ }^{29}$, em grande parte por conta dos primeiros sofrerem modificações constantemente. É muito comum, inclusive, como se mostrará na última parte deste artigo, que biomas e formações vegetais estejam atravessados por limites internacionais e, por conta disso, sujeitos a diferentes legislações ambientais. Além disso, a escala temporal dos territórios é bem menor do que a dos ecossistemas, daí a existência de distintas e diferentes territorialidades em um mesmo bioma ou formação vegetal ao longo do tempo.

Com efeito, os territórios apresentam estreita correlação com os ambientes onde são estabelecidos; pode-se afirmar, inclusive, que determinadas territorialidades só existem em função de condições ambientais específicas, sobretudo, quando o que está em questão é o acesso a recursos energéticos ou o uso do solo.

Em termos mais sintéticos, pode-se considerar que o território não se restringe à demarcação ou simples ocupação do espaço geográfico; ele contempla o uso desse espaço com todas as suas possibilidades e condicionantes ambientais, considerando as

\footnotetext{
27 Milton Santos, "Por uma Geografia nova: da crítica da Geografia a uma Geografia crítica" (São Paulo: Edusp, 2002 [1978]): p. 232. O autor explica que o "Estado-nação é essencialmente formado de três elementos: 1) o território; 2) um povo; 3) a soberania".

${ }^{28}$ Antonio Carlos Robert de Moraes, "Bases da formação territorial do Brasil", Geografares, n 2 (2001): p. 105-107.

${ }^{29}$ Marcelo Lopes de Souza, "Ambientes e territórios: uma introdução à Ecologia Política" (Rio de Janeiro: Bertrand Brasil, 2019$)$ : p. 84.
} 
várias relações de poder que se justapõem e acompanham ou conflitam com os modos de vida e práticas culturais dos grupos humanos presentes.

\section{A ABORDAGEM PALEOTERRITORIAL}

As diferentes territorialidades e os distintos usos que delas decorrem podem deixar marcas na paisagem, como o presente autor sugeriu em um parágrafo precedente. Esse entendimento abriu caminho para que Rogério Ribeiro de Oliveira apresentasse o conceito de paleoterritório, resultado da aglutinação do afixo palaiós (que vem do grego e significa antigo) com território, por ele definido como "o espaço geográfico sobre o qual um grupo [humano] encontra e estabelece suas condições de sobrevivência"30, o que inclui ocupação, uso e significação social.

Os paleoterritórios, portanto, raramente correspondem aos paleoambientes por duas razões fundamentais: a primeira é que estes últimos têm sua existência vinculada à escala geológica, bem mais remota que a escala correspondente ao tempo histórico, onde os paleoterritórios devem ser incluídos; a segunda razão, em parte associada à primeira, decorre do fato de os paleoambientes não dependerem da territorialidade e trabalho humanos para sua constituição genética. A discussão sobre a importância do trabalho humano na constituição de paleoterritórios e na modificação da paisagem ganha importância aqui. De modo geral, como bem registraram Marcela Kropf, Rogério Oliveira e Adi Estela Lazos Ruiz ${ }^{31}$, a busca por condições de existência física e os mecanismos culturais estão diretamente relacionados à apropriação e transformação da paisagem. Com o passar do tempo, as marcas ali impressas (por vezes, ocultas pela sucessão ecológica) irão se espacializar e se sobrepor como paleoterritórios. Outro aspecto relevante é que, mesmo em termos do tempo histórico, o afixo paleo (palaiós) não deverá indicar, necessariamente, uma antiguidade muito distante. Em muitas

\footnotetext{
30 Rogério Ribeiro de Oliveira, "Mata Atlântica, paleoterritórios e História Ambiental”, Ambiente e Sociedade, $n^{\circ} 2$, (2007): p. 13.

31 Marcela Stüker Kropf, Rogério Ribeiro de Oliveira e Adi Estela Lazos Ruiz, "Sujeitos ocultos na paisagem: desvelando a cultura material e o trabalho humano", Estudios Rurales, vol. 10 - n 19, (2020): p. 03-04.
} 
situações, uma determinada paisagem poderá apresentar os efeitos cumulativos de diferentes usos paleoterritoriais, datados de não mais do que um ou dois séculos.

Como bem definiu Rogério Ribeiro de Oliveira, os paleoterritórios são a "espacialização das resultantes ecológicas decorrentes do uso dos ecossistemas por populações passadas (ou de uma atividade econômica) na busca por suas condições de existência" ${ }^{\text {"2 }}$. Essas resultantes ecológicas estão diretamente relacionadas às diferentes racionalidades de quem usa o solo e interage com o ecossistema circundante: se, por exemplo, houver um uso predatório em ambiente florestal, isso poderá levar ao aparecimento de florestas secundárias ou, no limite, à sua completa eliminação; se, ao contrário, o uso for (ou se aproximar do) sustentável, não deverão ser vistos impactos de grande magnitude ${ }^{33}$. É bom que se diga, a título de esclarecimento, que as populações tradicionais não são, necessariamente, sustentáveis ${ }^{34}$ e há casos de sociedades anteriores ao aparecimento do capitalismo que colapsaram ou passaram por situações que incluíam perdas demográficas e escassez de recursos. O prestigiado escritor Jared Diamond, ao considerar o assunto, afirmou que as ruínas de antigas cidades indicariam abandonos provocados "por problemas ecológicos, pelo fato de as pessoas terem destruído inadvertidamente os recursos ambientais dos quais as suas sociedades dependiam"35. E ainda acrescentou que o "ecocício", como ele preferiu chamar o suicídio não intencional ocasionado por razões ecológicas, está sendo confirmado por pesquisadores de diversas formações, como historiadores, arqueólogos e paleontólogos. Nesse sentido, o "débito ecológico", visível em várias regiões do mundo, não deverá ficar apenas na conta dos grandes capitalistas, muito embora seja inegável o gravíssimo quadro de degradação ambiental por eles desencadeado.

A compreensão de distintos paleoterritórios deverá incluir o estudo de diferentes atividades e processos associados à sua formação, como a prática da pecuária extensiva, a agricultura e o domínio do fogo.

\footnotetext{
32 Rogério Ribeiro de Oliveira, "Mata Atlântica, paleoterritórios e História Ambiental", Ambiente e Sociedade, n² 2, (2007): p. 13.

${ }^{33}$ Parte-se do entendimento que os impactos de grande magnitude constituem um problema para a manutenção da biodiversidade e preservação dos solos, o que não significa que todas as transformações realizadas no ambiente de floresta serão sempre degradantes.

${ }^{34}$ Ver a esse respeito as discussões presentes em: Rogério Ribeiro de Oliveira, "Mata Atlântica, paleoterritórios e História Ambiental", Ambiente e Sociedade, $n^{\circ}$ 2, (2007): p. 14-15 e também em Marcelo Lopes de Souza, "Ambientes e territórios: uma introdução à Ecologia Política" (Rio de Janeiro: Bertrand Brasil, 2019): p. 89-91.

35 Jared Diamond, "Colapso: como as sociedades escolhem o fracasso ou o sucesso" (Rio de Janeiro: Record, 2010): p. 17-19.
} 
O domínio do fogo amplia drasticamente o controle que uma sociedade tem sobre o seu território, condicionando o uso de seus recursos. O fogo é uma ferramenta fundamental para a agricultura de subsistência e adequado aos propósitos de regeneração da floresta ${ }^{36}$. A história do fogo produziu imensas transformações na paisagem do planeta, levando os ecossistemas ao desenvolvimento de progressivos processos de adaptação e infligindo severas alterações a todos os seus elementos constituintes ${ }^{37}$.

A formação de paleoterritórios no sudeste brasileiro, por exemplo, precisa ser associada à agricultura nômade, realizada em áreas que foram incendiadas e que, por isso, passaram por ciclos de regeneração. Esse tipo de agricultura tradicional é "responsável pela seleção de espécies e de tipos ecológicos especializados na ocupação de espaços abertos, ou seja, pelo pool de espécies pioneiras e secundárias iniciais disponível no ecossistema"38. As etapas iniciais do abandono das antigas roças induzem a gênese de paleoterritórios à medida que formações florestais as recobrem ${ }^{39}$.

Os paleoterritórios podem ser classificados em função de diferentes fatores e assumir tamanhos e formas diversas. Além disso, por constituírem um "repositório de histórias profundas da relação do homem com o meio"40, os paleoterritórios são delimitados a partir das diferentes configurações vegetacionais que resultam do trabalho humano, bem como de vestígios de antigas territorializações inscritas nas paisagens. Algumas dessas evidências se encontram encobertas pelos processos de sedimentação, outras ficam visíveis "al ojo experto del botánico (especies de plantas y sus estados sucesionales) o del arqueólogo (ocupaciones históricas anteriores), otras que se encuentran formando parte del cotidiano que a su vez las hace invisibles

\footnotetext{
${ }^{36}$ S. Hecht e D. Posey, "A preliminary results on soil management techniques of the Kayapó Indians", Advances in economic botany, vol. 7, (1989): 174-188.

${ }^{37} \mathrm{~N}$. Caldararo, "Human ecological intervention and the role of forest fires in human ecology", The science of the total environment, vol. $292-n^{\circ} 3$, (2002): 141-165.

${ }^{38}$ Rogério Ribeiro de Oliveira, "Mata Atlântica, paleoterritórios e História Ambiental", Ambiente e Sociedade, n 2, (2007): p. 16.

${ }^{39}$ Rogério Ribeiro de Oliveira, Patrícia Delamônica, Denise Flores Lima e Daniel Toffoli, "A gênese estrutural de um paleoterritório: a sucessão na floresta atlântica nos primeiros dez anos após uso por populações caiçaras", Pesquisa Botânica, vol. 59, (2008): 113-128.

40 Marcela Stüker Kropf, Rogério Ribeiro de Oliveira e Adi Estela Lazos Ruiz, "Sujeitos ocultos na paisagem: desvelando a cultura material e 0 trabalho humano", Estudios Rurales, vol. 10 - n 19, (2020): p. 03-04.
} 
(puentes o caminos antiguos) y otras que son visibles y reconocidas por todos (monumentos conservados)" ${ }^{\prime 4}$.

Essa discussão reforça a transversalidade da abordagem paleoterritorial, principalmente por conta do necessário diálogo da pesquisa histórica com os estudos botânicos e arqueológicos.

Apesar de não ser um sinônimo ou equivalente de paleoterritório, o conceito de Arqueologia da Paisagem fornece um debate amadurecido sobre a relação entre as ações humanas e a constituição de paisagens. Uma aproximação teórica entre a Arqueologia e a Geografia Cultural possibilitou a leitura da paisagem como mais do que o simples resultado de processos socioculturais. Na avaliação de Ana Cristina de Sousa, tanto arqueólogos como geógrafos culturais têm sido capazes de elaborar "profícuas reflexões sobre a forma como a paisagem atua na configuração das sociedades, imprimindo valores, normatizando e influenciando comportamentos, legitimando e naturalizando desigualdades, bem como exprimindo resistências" ${ }^{2}$.

Uma maior aproximação entre historiadores ambientais, arqueólogos e botânicos (a exemplo do que ocorreu com o conceito de Arqueologia da Paisagem) poderá aperfeiçoar os métodos e ampliar o alcance dos estudos paleoterritoriais.

Não obstante, em trabalho recente, Rogério Ribeiro de Oliveira ${ }^{43}$ apresentou uma tipologia que contemplava paleoterritórios associados à: 1) produção de alimento, 2) produção de energia e 3) circulação de pessoas durante o século XIX ou em período anterior. A riqueza das análises propostas apresenta grande contribuição, principalmente metodológica, para as pesquisas em História Ambiental.

\footnotetext{
${ }^{41}$ Adi Estela Ruiz, Rogério Ribeiro de Oliveira e Alexandro Solórzano, "Buscando la Historia en los bosques: el papel de los macrovestigios y de la vegetación en la Mata Atlántica", Fronteiras: Journal of Social, Technological and Environmental Science, vol. $06-\mathrm{n}^{\circ} 01$ (2017): p. 164.

$\mathrm{Na}$ tradução do autor: ao olhar perito do botânico (espécies de plantas e seus estados sucessionais) ou do arqueólogo (ocupações históricas anteriores), outras que fazem parte da rotina diária que, por sua vez, as torna invisíveis (pontes ou estradas antigas) e outras que são visíveis e reconhecidas por todos (monumentos preservados).

${ }^{42}$ Ana Cristina de Sousa, "Arqueologia da paisagem e a potencialidade interpretativa dos espaços sociais', Revista Habitus, vol. $03-\mathrm{n}^{\circ} 02,(2005)$ : p. 295.

43 Rogério Ribeiro de Oliveira, "Fruto da terra e do trabalho humano: paleoterritórios e diversidade da Mata Atlântica no sudeste brasileiro", Revista de História Regional, n² 20-2, (2015): 277-299;
} 


\section{PALEOTERRITÓRIOS EM FAIXAS DE FRONTEIRA}

Alguns estudos sobre migrações e interações transfronteiriças ${ }^{44}$ e também sobre formações florestais e áreas protegidas em faixas de fronteira ${ }^{45}$ vêm contribuindo significativamente para o entendimento das relações entre território e ambiente. Esses estudos apresentam a fronteira para além da delimitação entre distintos territórios, abrindo caminho para identificação dos vestígios do trabalho humano nos ambientes fronteiriços.

Não se pode acreditar que os biomas e formações vegetais sempre estarão inscritos nos limites nacionais. A floresta equatorial amazônica, por exemplo, está presente na região norte do Brasil, em uma fração da América Andina e no conjunto das Guianas. Nesse complexo e extenso domínio, há várias terras indígenas, recursos naturais disponíveis, atividades produtivas e áreas protegidas. Rebeca Steiman ${ }^{46}$ cartografou e analisou uma dúzia dessas áreas de proteção transfronteiriça na região. Além de ser grande o seu número, abrangendo a maioria dos países participantes do domínio amazônico, a autora constatou a contiguidade dessas áreas em ambos os lados dos limites internacionais.

Nas três áreas de proteção que envolvem os estados brasileiros do Amapá e Pará com as Guianas e o Suriname ${ }^{47}$, Steiman identificou a existência no lado brasileiro de um "grande bloco de terras, conectado por diversas áreas protegidas, que mantém entre si não apenas processos ecológicos, mas interações entre habitantes e entre frentes de exploração madeireira e garimpeira"48.

\footnotetext{
44 Destacam-se para os propósitos deste artigo: 1) Edgar Andrés Niño, "Migração, cidades e fronteiras: a migração venezuelana nas cidades fronteiriças do Brasil e da Colômbia", Revista Espaço Aberto, vol. 10 - n 1, (2020): 51-67; 2) Lia Osório Machado, "Estado, territorialidade, redes: cidades-gêmeas na zona de fronteira sul-americana". In: Continentes em chamas: globalização e território na América Latina, organizado por Maria Laura Silveira (Rio de Janeiro: Civilização Brasileira, 2005); 3) Lia Osório Machado, Letícia Parente Ribeiro e Lício Caetano Monteiro, "Geopolítica fragmentada: interações transfronteiriças entre o Acre (BR), o Peru e a Bolívia”, Revista Colombiana de Geografía, vol. 23 - n 02, (2014): 15-30.

45 Destacam-se para os propósitos deste artigo: 1) Marcela Stuker Kropf e Rogério Ribeiro Oliveira, "Áreas protegidas fronteiriças", Revista Perspectiva Geográfica, vol. $08-n^{\circ}$ 09, (2013): 01-20; 2) Marcela Stuker Kropf, Silvia Lilian Ferro e Rogério Ribeiro de Oliveira, "Biodiversidade, sociedades e Estados: lições de cooperação em áreas protegidas transfronteiriças", Revista Sociedade e Natureza, vol. 31, (2019): 01-21; 3) Rebeca Steiman, "Áreas protegidas nas zonas de fronteira internacional da Amazônia brasileira", (Tese de doutoramento apresentada ao PPGG da Universidade Federal do Rio de Janeiro, 2008).

${ }^{46}$ Rebeca Steiman, "Áreas protegidas nas zonas de fronteira internacional da Amazônia brasileira", (Tese de doutoramento apresentada ao PPGG da Universidade Federal do Rio de Janeiro, 2008): p. 125.

47 Tumucumaque - Amazonien (Amapá e Guiana Francesa), Tumucumaque - Sipaliwini (Pará e Suriname) e Grão-Pará - Wai-Wai (Pará e Guiana). ${ }^{48}$ Rebeca Steiman, "Áreas protegidas nas zonas de fronteira internacional da Amazônia brasileira", (Tese de doutoramento apresentada ao PPGG da Universidade Federal do Rio de Janeiro, 2008): p. 131.
} 
O trabalho da referida autora aponta para essa complexidade das relações entre território e ambiente na porção norte da faixa de fronteira brasileira ${ }^{49}$. Além do mais, abre caminho para se investigar as resultantes ecológicas desencadeadas pelas atividades ali desenvolvidas, o que possibilita a realização de estudos paleoterritoriais nas áreas de proteção mencionadas.

A fronteira brasileira, além de muito extensa $\left(16.885,7 \mathrm{Km}^{50}\right)$, apresenta grande diversidade ecológica, cultural e econômica, o que constitui um amplo campo para estudos ambientais balizados pela abordagem paleoterritorial.

É importante enfatizar que os estudos sobre paleoterritórios ainda são muito recentes e pouco $\operatorname{conhecidos}^{51}$, eles não apresentam, como se mencionou na seção anterior deste artigo, a abrangência e o amadurecimento das pesquisas arqueológicas. Não obstante, algumas similitudes podem ser estabelecidas entre ambos: procuram identificar antigas formas de ocupação e territorialização do espaço, buscam compreender as manifestações culturais impressas em antigas paisagens, entre outros. Por outro lado, os paleoterritórios focalizam as transformações ecológicas resultantes do trabalho humano no ambiente e as pesquisas arqueológicas dedicam maior atenção à cultura material, considerada a "principal fonte de estudo e via de acesso a uma sociedade do passado" 52

Nesse contexto, ao se pensar nos estudos fronteiriços, cumpre mencionar o projeto "Arqueologia sem fronteiras", fruto da cooperação entre Argentina e Brasil para pesquisa arqueológica da Província de Misiones e do oeste de Santa Catarina. Para Daniel Laponte e Mirian Carbonera, "a notável quantidade de sítios arqueológicos registrados na área e a aposta no projeto de pesquisa binacional, outorgam uma

\footnotetext{
${ }^{49}$ No caso brasileiro, a faixa de fronteira tem $150 \mathrm{~km}$ de extensão a contar do limite territorial nacional. A Lei 6.634 , de 02 de maio de 1979 , não apenas delimitou essa faixa como a considerou indispensável à segurança nacional. Essa informação foi ratificada no $20^{\circ}$ artigo da Constituição de 1988, especificamente em seu $2^{\circ}$ inciso: "A faixa de até cento e cinquenta quilômetros de largura, ao longo das fronteiras terrestres, designada como faixa de fronteira, é considerada fundamental para defesa do território nacional, e sua ocupação e utilização serão reguladas em lei”. Não obstante, cada país define o tamanho e a função de sua faixa de fronteira. Peru e Bolívia, por exemplo, apresentam uma faixa de fronteira bem mais estreita, com apenas $50 \mathrm{~km}$ de extensão.

50 Segundo levantamento disponivel em: https://www.funag.gov.br/ipri/images/analise-e-informacao/fronteiras-terrestres-brasil-13052015.pdf (consulta realizada: 24 de fevereiro de 2021).

51 Os primeiros trabalhos de Rogério Ribeiro de Oliveira sobre o conceito são de meados da primeira década deste século.

52 Jairo Henrique Rogge, "Fenômenos de fronteira: um estudo das situações de contato entre os portadores das tradições cerâmicas pré-históricas no Rio Grande do Sul", (Tese de doutoramento apresentada ao Programa de Pós-graduação em História da Unisinos, 2004): p. 58.
} 
incomparável oportunidade para avançar na produção de novos conhecimentos sobre a história pré-colonial dessa ampla região"53.

Assim como os sítios arqueológicos, os paleoterritórios também podem atravessar as fronteiras nacionais. Em se tratando da faixa de fronteira, a abordagem paleoterritorial poderá servir para a elucidação das características do entorno da área de estudo e não apenas para a identificação das transformações ecológicas resultantes do trabalho humano in situ. As atividades que originam um paleoterritório geralmente expressam uma organização sócio-espacial mais ampla ou, pensando no espaço fronteiriço, expressam diferentes formas de organização territorial que se combinam complexamente. Além do mais, paleoterritórios que estejam atravessados por limites internacionais poderão ser estudados por pesquisadores de países diferentes, agregando experiências e perspectivas de análise diversas aos estudos de História Ambiental.

Uma importante interação que ocorre ao longo da faixa de fronteira entre o Brasil e seus vizinhos sul-americanos é a constituição de cidades-gêmeas, que, no entendimento de Lia Osório Machado ${ }^{54}$, é o "meio geográfico que melhor caracteriza a zona de fronteira". As cidades-gêmeas apresentam uma dinâmica muito pautada nas relações que estabelecem entre si. Elas foram analisadas pela referida autora a partir de elementos, como trabalho, fluxos de capital, terra e outros recursos naturais e também serviços de consumo coletivo.

Um dos casos mencionados em seu trabalho, o das cidades-gêmeas de Brasiléia (Acre-Brasil) e Cobija (Pando-Bolívia), oferece um cenário convidativo para os estudos ambientais. Segundo Lia Machado, muitos brasileiros migram para a cidade boliviana "devido ao preço mais barato da terra e à baixa restrição na proteção ambiental da extração da madeira nobre" 55 .

\footnotetext{
53 Daniel Laponte e Mirian Carbonera, "Arqueologia sem fronteiras: projeto de cooperação binacional para o estudo arqueológico da Província de Misiones (Argentina) e oeste de Santa Catarina (Brasil)", (Projeto de Pesquisa em versão digital, 2013): p.47. Disponível em: http://www.portaldeperiodicos.unisul.br/index.php/memorare grupep/article/view/1885.

54 Lia Osório Machado, "Estado, territorialidade, redes: cidades-gêmeas na zona de fronteira sul-americana". In: Continentes em chamas: globalização e território na América Latina, organizado por Maria Laura Silveira (Rio de Janeiro: Civilização Brasileira, 2005): p. 260.

55 Lia Osório Machado, "Estado, territorialidade, redes: cidades-gêmeas na zona de fronteira sul-americana". In: Continentes em chamas: globalização e território na América Latina, organizado por Maria Laura Silveira (Rio de Janeiro: Civilização Brasileira, 2005$)$ : p. 271.
} 
As diferenças na definição de normas e de rigor na preservação ambiental entre países vizinhos, as tramas que envolvem os sistemas produtivos dessas cidades-gêmeas e os complexos fluxos legais e ilegais que costuram seus diferentes tecidos urbanos não apenas reforçam o entendimento, cada vez mais difundido, de que fronteiras internacionais constituem espaços de troca, interação e conflito, eles abrem um importante campo de estudos para a História Ambiental.

Investigar as marcas impressas pelo trabalho humano nos ambientes fronteiriços, situá-las no tempo e perceber em que medida influenciaram a atual organização do território traz um ganho expressivo para o arcabouço teórico da disciplina. De outra parte, o que está em questão é a contribuição da análise paleoterritorial para o entendimento da interação entre diferentes formações socioeconômicas/sociopolíticas/socioculturais na faixa de fronteira.

Nesse contexto, a identificação de marcadores - que, usualmente, estão no meio biótico, como espécies indicadoras de atividades antropogênicas pretéritas ou até mesmo fragmentos de construções, ferramentas e lixo sólido - é fundamental para se entender as possíveis sobreposições de paleoterritórios nas faixas de fronteira, ou seja, uma forma de construir a história da fronteira tendo o ambiente como fio condutor, como referencial imprescindível para as ações humanas.

Os estudos sobre fronteiras tradicionalmente privilegiam a abordagem políticoterritorial. As fronteiras são vistas como "condição e resultado das ações sociais em coerência com seu tempo [...] os movimentos que originam uma fronteira, sofrendo mudanças ao longo do tempo, também podem condicionar a [sua] obsolescência" ${ }^{\prime 56}$, como afirmou Márcio Cataia. Em outra perspectiva, as fronteiras apresentam continuidades (como através de algumas formações florestais, áreas protegidas ou pela movimentação de indígenas) e descontinuidades (quando confrontam espaços diferentes em termos de produção, organização do território e manifestação cultural ou mesmo quando evidenciam distintas temporalidades e ritmos de desenvolvimento). As marcas dessas complexas relações fronteiriças, expressas por diversas resultantes ecológicas, se analisadas pela abordagem paleoterritorial, gerarão ganhos expressivos

56 Márcio Cataia, "Território nacional e fronteiras internas. A fragmentação do território brasileiro", (Tese de doutoramento apresentada ao PPGG da Universidade de São Paulo, 2001): p. 15. 
para as pesquisas desenvolvidas por historiadores e demais cientistas sociais que privilegiem o enfoque ambiental.

Essa dinâmica das faixas de fronteira deve, inclusive, ser considerada quando da formulação de políticas públicas e da cooperação e responsabilização pelo ambiente fronteiriço. Assim, como bem destacaram Marcela Kropf e Rogério Oliveira ${ }^{57}$, a criação de dois importantes parques nacionais, o brasileiro Iguaçu e o argentino Iguazú, não teria sido motivada apenas pela preservação da formação florestal contínua, mas, dentre outras coisas, pela segurança da fronteira.

Outra importante dimensão da dinâmica fronteiriça compreende os impactos socioambientais de grandes obras, como a construção da represa formada pela hidrelétrica Itaipu binacional (Brasil - Paraguai). A finalização das obras e a formação do reservatório da usina, em fins de 1982, não apenas forçaram a expropriação de um grande número de agricultores da região, mas também tornaram necessária a desocupação de algumas vilas ali estabelecidas - como é o caso de Alvorada do Iguaçu, na época com 3.700 moradores $^{58}$ - e também a remoção de ossadas dos cemitérios localizadas na área que seria inundada ${ }^{59}$.

Nesse caso, houve um grande transtorno gerado pela migração forçada da população local, o que incluiu perdas materiais e perdas associadas à topofilia. Além disso, com a inundação provocada pela represa e a profunda alteração da paisagem, tornaram-se pouquíssimo viáveis os estudos paleoterritoriais na região.

A despeito do grande desafio apresentado na situação supracitada e em outras onde a realização de trabalhos de campo possa estar vetada, a extensa fronteira entre o Brasil e seus vizinhos sul-americanos reserva muitas possibilidades para investigação das resultantes ecológicas de distintas e diferentes territorialidades passadas.

\footnotetext{
${ }^{57}$ Marcela Stuker Kropf e Rogério Ribeiro Oliveira, "Áreas protegidas fronteiriças", Revista Perspectiva Geográfica, vol. 08 - n $09,(2013)$ : p. 13. 58 Disponível em: https://catve.com/noticia/6/78715/ruinas-de-antiga-cidade-reaparecem-no-lago-de-itaipu Consulta realizada em 16 de outubro de 2020.

59 Kleber Dreicy Melchior, "A migração dos mortos: remanejamento de cemitérios na região do lago de Itaipu", (Dissertação de mestrado apresentada à Universidade Estadual do Oeste do Paraná, 2012).
} 


\section{CONSIDERAÇÕES FINAIS}

A influência mútua entre o trabalho realizado por diferentes grupos sociais e o ambiente, que grosso modo constitui o objeto de estudo da História Ambiental, se expressa por relações territoriais que marcam as paisagens. É difícil negar que os ambientes constituem um palco interativo das relações de poder espacialmente delimitadas. Diante disso, a abordagem paleoterritorial proposta nos trabalhos de Rogério Ribeiro de Oliveira oferece novas perspectivas, principalmente metodológicas, para as pesquisas históricas que ambicionem romper com a dicotomia entre sociedade e natureza.

Este artigo procurou apontar, ainda que de forma introdutória, a importância de estudos paleoterritoriais em faixas de fronteira, espaços marcados por complexas e densas relações de troca e, tomando como referência o Brasil, onde se acham importantes formações florestais e áreas de proteção que ultrapassam os limites nacionais. Os últimos trabalhos citados pelo autor apontam situações em que as relações fronteiriças - estimuladas por diferentes legislações, assimetrias políticoeconômicas ou obra de grande envergadura - direcionaram ações e movimentos populacionais com fortes e visíveis repercussões ambientais e, consequentemente, grande importância histórica.

A expectativa é de que as breves discussões propostas neste artigo tenham servido para estimular o leitor a fazer apontamentos e questões de pesquisa sobre o tema.

\section{AgRADECIMENTOS}

O autor agradece ao Prof. Dr. Rogério Ribeiro de Oliveira pelo estímulo ao desenvolvimento deste trabalho e pelas importantes sugestões dadas quando da leitura de sua primeira versão. O agradecimento se estende aos revisores da HALAC que contribuíram com o aperfeiçoamento e finalização do artigo. Cumpre mencionar o 
apoio financeiro do Departamento de Geografia e Meio Ambiente da PUC-Rio, através da concessão de bolsa CCPG.

\section{REFERÊNCIAS}

Adi Estela Ruiz, Rogério Ribeiro de Oliveira e Alexandro Solórzano, "Buscando la Historia en los bosques: el papel de los macrovestigios y de la vegetación en la Mata Atlántica", Fronteiras: Journal of Social, Technological and Environmental Science, vol. $06-\mathrm{n}^{\circ} 01$ (2017): p. 163-182.

Álvaro Luiz Heidrich, "Conflitos territoriais na estratégia de preservação da natureza". In Territórios e territorialidades: teorias, processos e conflitos, organizado por Marcos Aurélio Saquet e Eliseu Savério Sposito (Rio de Janeiro: Consequência, 2015).

Ana Cristina de Sousa, "Arqueologia da paisagem e a potencialidade interpretativa dos espaços sociais', Revista Habitus, vol. 03 - n02, (2005): p. 291-300.

Antonio Carlos Robert de Moraes, "Bases da formação territorial do Brasil", Geografares, $n^{\circ} 2$ (2001): p. 105-113.

Claudia Leal, "Aguzar la mirada colectiva, el gran desafío de la Historia Ambiental latinoamericana", Historia Social, vol.36, (2019): 243-268.

Daniel Laponte e Mirian Carbonera, "Arqueologia sem fronteiras: projeto de cooperação binacional para o estudo arqueológico da Província de Misiones (Argentina) e oeste de Santa Catarina (Brasil)", (Projeto de Pesquisa em versão digital, 2013).

Donald Worster, "Para fazer História Ambiental", Estudos Históricos, vol. 4 - n 8, (1991): 198-215.

Edgar Andrés Niño, "Migração, cidades e fronteiras: a migração venezuelana nas cidades fronteiriças do Brasil e da Colômbia", Revista Espaço Aberto, vol. 10 - n 1, (2020): 51-67.

Enrique Leff, "Construindo a História Ambiental da América Latina", Revista Esboços, $\mathrm{n}^{\circ} 13,(2003): 11-29$.

Jairo Henrique Rogge, "Fenômenos de fronteira: um estudo das situações de contato entre os portadores das tradições cerâmicas pré-históricas no Rio Grande do Sul", (Tese de doutoramento apresentada ao Programa de Pós-graduação em História da Unisinos, 2004). 
Jared Diamond, "Colapso: como as sociedades escolhem o fracasso ou o sucesso" (Rio de Janeiro: Record, 2010).

José Augusto Drummond, "A História Ambiental: temas, fontes e linhas de pesquisa", Estudos Históricos, Rio de Janeiro, vol.4 - n 8, (1991): 177-197.

José Augusto Pádua, "As bases teóricas da História Ambiental", Estudos Avançados, $\mathrm{n}^{\circ}$ 24 - 68, (2010): 81-101.

Kleber Dreicy Melchior, "A migração dos mortos: remanejamento de cemitérios na região do lago de Itaipu", (Dissertação de mestrado apresentada à Universidade Estadual do Oeste do Paraná, 2012).

Lia Osório Machado, "Estado, territorialidade, redes: cidades-gêmeas na zona de fronteira sul-americana". In: Continentes em chamas: globalização e território na América Latina, organizado por Maria Laura Silveira (Rio de Janeiro: Civilização Brasileira, 2005).

Lia Osório Machado, Letícia Parente Ribeiro e Lício Caetano Monteiro, "Geopolítica fragmentada: interações transfronteiriças entre o Acre (BR), o Peru e a Bolívia", Revista Colombiana de Geografía, vol. 23 - nº 02, (2014): 15-30.

Marcela Stuker Kropf e Rogério Ribeiro Oliveira, "Áreas protegidas fronteiriças", Revista Perspectiva Geográfica, vol. 08 - nº 09, (2013): 01-20.

Marcela Stuker Kropf, Silvia Lilian Ferro e Rogério Ribeiro de Oliveira, "Biodiversidade, sociedades e Estados: lições de cooperação em áreas protegidas transfronteiriças", Revista Sociedade e Natureza, vol. 31, (2019): 01-21.

Marcela Stüker Kropf, Rogério Ribeiro de Oliveira e Adi Estela Lazos Ruiz, "Sujeitos ocultos na paisagem: desvelando a cultura material e o trabalho humano", Estudios Rurales, vol. 10 - n 19, (2020): 01-20.

Marcelo Lopes de Souza, "Ambientes e territórios: uma introdução à Ecologia Política" (Rio de Janeiro: Bertrand Brasil, 2019).

Márcio Cataia, "Território nacional e fronteiras internas. A fragmentação do território brasileiro", (Tese de doutoramento apresentada ao PPGG da Universidade de São Paulo, 2001).

Milton Santos, "Por uma Geografia nova: da crítica da Geografia a uma Geografia crítica" (São Paulo: Edusp, 2002 [1978]).

N. Caldararo, "Human ecological intervention and the role of forest fires in human ecology", The science of the total environment, vol. 292 - n 3, (2002): 141-165.

Paulo Cesar da Costa Gomes, "Geografia fin-de-siècle: o discurso sobre a ordem espacial do mundo e o fim das ilusões". In: Explorações geográficas, organizado por Iná 
Elias de Castro, Paulo César da Costa Gomes e Roberto Lobato Corrêa (Rio de Janeiro: Bertrand Brasil, 1997): 13-42.

Rebeca Steiman, "Áreas protegidas nas zonas de fronteira internacional da Amazônia brasileira", (Tese de doutoramento apresentada ao PPGG da Universidade Federal do Rio de Janeiro, 2008).

Rogério Haesbaert, "O mito da desterritorialização: do "fim dos territórios" à multiterritorialidade" (Rio de Janeiro: Bertrand Brasil, 2004).

Rogério Ribeiro de Oliveira, "Mata Atlântica, paleoterritórios e História Ambiental", Ambiente e Sociedade, $\mathrm{n}^{\circ}$ 2, (2007): 11-23.

Rogério Ribeiro de Oliveira, "Fruto da terra e do trabalho humano: paleoterritórios e diversidade da Mata Atlântica no sudeste brasileiro", Revista de História Regional, n ${ }^{\circ}$ 20-2, (2015): 277-299.

Rogério Ribeiro de Oliveira, Patrícia Delamônica, Denise Flores Lima e Daniel Toffoli, "A gênese estrutural de um paleoterritório: a sucessão na floresta atlântica nos primeiros dez anos após uso por populações caiçaras", Pesquisa Botânica, vol. 59, (2008): 113-128.

S. Hecht e D. Posey, "A preliminary results on soil management techniques of the Kayapó Indians", Advances in economic botany, vol. 7, (1989): 174-188.

\title{
Environments and paleoterritories in border bands: perspectives for Environmental History
}

\begin{abstract}
The present work makes a brief analysis of how the paleoterritorial approach can contribute to the environmental research in the border bands, marked by different temporalities, differences in terms of production and organization of the territory, in addition to the presence of forest formations and protected areas that exceed international limits. The concepts of environment and territory and their important overlaps are presented, which proved to be a prerequisite for the discussion on paleoterritories and borders. All of this preceded by an appreciation of the context of the emergence, the objectives and perspectives of Environmental History. The paleoterritory is defined as the spatialization of ecological results from past territorialization and appears as a relevant contribution to analyze the past from new perspectives. Examples of border relations linked to the environmental issue are mentioned and, therefore, serve as a reference for historical studies sensitive to the theme.
\end{abstract}

Keywords: Paleoterritory; Environment; Border; Environmental History. 